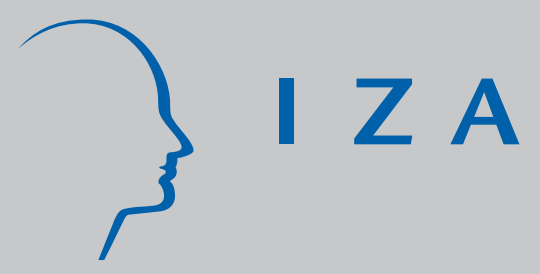

IZA DP No. 3225

The Trend in Female Labour Force Participation: What Can Be Expected for the Future?

Rob Euwals

Marike Knoef

Daniel van Vuuren

December 2007 


\title{
The Trend in Female Labour Force Participation: What Can Be Expected for the Future?
}

\author{
Rob Euwals \\ CPB, Netspar and IZA \\ Marike Knoef \\ Tilburg University, Netspar and CentERdata \\ Daniel van Vuuren \\ $C P B$ and Netspar
}

Discussion Paper No. 3225

December 2007

\author{
IZA \\ P.O. Box 7240 \\ 53072 Bonn \\ Germany \\ Phone: +49-228-3894-0 \\ Fax: +49-228-3894-180 \\ E-mail: iza@iza.org
}

Any opinions expressed here are those of the author(s) and not those of the institute. Research disseminated by IZA may include views on policy, but the institute itself takes no institutional policy positions.

The Institute for the Study of Labor (IZA) in Bonn is a local and virtual international research center and a place of communication between science, politics and business. IZA is an independent nonprofit company supported by Deutsche Post World Net. The center is associated with the University of Bonn and offers a stimulating research environment through its research networks, research support, and visitors and doctoral programs. IZA engages in (i) original and internationally competitive research in all fields of labor economics, (ii) development of policy concepts, and (iii) dissemination of research results and concepts to the interested public.

IZA Discussion Papers often represent preliminary work and are circulated to encourage discussion. Citation of such a paper should account for its provisional character. A revised version may be available directly from the author. 


\title{
ABSTRACT \\ The Trend in Female Labour Force Participation: What Can Be Expected for the Future?
}

\begin{abstract}
During the 1980s and 1990s, the Netherlands experienced a strong increase in the labour force participation of women. This study investigates the increase of participation over the successive generations of women, and produces an educated guess for future participation. For this purpose, we estimate a binary age-period-cohort model for the generations born between 1925 and 1986, using data from the Dutch Labour Force Survey 1992-2004. The results indicate that the increasing level of education, the diminishing negative effect of children, and unobserved cohort effects have played an important role. According to our estimates, the increase in unobserved cohort effects has stopped since the generation born in 1955. This result is in line with results of studies on social norms and attitudes towards the combination of female employment and family responsibilities, which show a similar pattern over the successive generations. We observe that future participation growth importantly depends on the evolvement of attitudes towards the combination of paid work and children. We have therefore constructed two alternative future scenarios, the first with constant norms with respect to this factor, and the second with a further evolvement. It is estimated that the remaining growth will compensate for about one third of the structural fiscal deficit caused by population ageing in the Netherlands.
\end{abstract}

JEL Classification: J11, J21

Keywords: female labour force participation, age-period-cohort-analysis, future development

Corresponding author:

Rob Euwals

CPB Netherlands Bureau for Economic Policy Analysis

P.O. Box 80510

2508 GM Den Haag

The Netherlands

E-mail: r.w.euwals@cpb.nl

\footnotetext{
* The authors thank Frank Cörvers, Casper van Ewijk, Marien Ferdinandusse, Saskia Keuzenkamp, Peter Kooiman, Rocus van Opstal, Harry ter Rele, Federica Teppa, Coen Teulings, Maarten Vendrik, Ed Westerhout, and participants of the ESPE 2007 in Chicago, the EALE 2007 in Oslo, the 2007 COST meeting in The Hague, and seminars at CPB, DNB, Netspar, and Tilburg University for useful comments, and Adri den Ouden and Janneke Rijn for research assistance. Statistics Netherlands is acknowledged for providing the data.
} 


\section{Introduction}

Over the last decades, many countries experienced an increase in the labour force participation of women. The Netherlands are an exceptional example, as female participation more than doubled, from $31 \%$ in 1975 to $69 \%$ in 2006 (OECD, various years). This development reflects a major change in Dutch society and has several dimensions. First, an important social dimension is that women are becoming more integrated into formal production. Although women lag behind men considerably in terms of (full-time) employment and wages, like in many other countries, at least they are catching up. Second, an important economic dimension is that an increase in the female contribution to formal production leads to higher economic growth. The high growth rates of the Dutch economy at the end of the 1990s can be attributed partly to the substantial increase in female participation. Third, the developments have a fiscal and demographic dimension as well. It is widely believed that an increase in the participation rate contributes to the fiscal sustainability of the welfare state, which is under pressure due to the ageing of society. An important portion of the foreseen fiscal gap could be prevented by an increment in the labour force participation (Apps 1991, Aaberge, Colombino \& Holmøy 2004, van Ewijk, Draper, ter Rele \& Westerhout 2006).

The first principal goal in this paper is to decompose the growth in the female participation rate over the period 1992-2004. Do younger cohorts have a larger probability to be employed than older cohorts? Or did the favourable economic conditions in the late 1990s encourage women to participate in the labour market? Our modelling approach allows us to make a full decomposition of the observed growth during the period mentioned. Our second aim is to determine which factors will remain important in the upcoming decades. While some factors may not be as important for future growth as they have been in the past, others are likely to remain important. The effects of the various factors on the future development of the 
participation rate are quantified in two scenarios. As an aside, we will also give some indication on the effect of the prospected participation increase on the fiscal sustainability of government finances in the Netherlands. Typically, most studies on the impact of ageing on government finances do not assess the partial impact of participation growth on fiscal sustainability, but rather take as given one central projection (see, e.g., Cournède \& Gonand 2006, Roeger 2002, Rother, Catenaro \& Schwab 2002).

To answer these research questions, we estimate a binary choice model for participation of women born between 1925 and 1986 on the basis of the Dutch Labour Force Survey 1992-2004. Our model specification includes various explanatory variables, such as education and household situation. Moreover, we employ two different identification strategies to disentangle the unexplained participation growth into unobserved age, period, and cohort effects. According to our interpretation, the age effect includes individual life-cycle decisions, like the timing of education and marriage. Period effects include cyclical and unobserved instantaneous effects, e.g. effects of policy changes. The unobserved cohort effect may be interpreted as societal changes in the orientation towards paid employment that are unrelated to education or children (i.e. these changes are not the result of a higher educational attainment and a lower fertility of the younger generations). Of course, apart from these unobserved effects, the model specification also includes age, period, and cohort effects which are correlated with observed variables. For instance, a part of the cohort effect is correlated with included variables such as educational attainment and fertility.

Estimation results show that both the observed and unobserved cohort effects have been crucial in spurring the female participation rate. Time effects have also played an important role during the 1990s. The negative relation between the unemployment rate and the participation rate suggests an 'encouraged worker effect', i.e. the favourable market conditions during 
the 1990s have attracted many females to participate in the labour market. An important finding is that observed factors (such as education and household situation) can fully 'explain' participation growth of generations born after 1955, but that unobserved cohort effects play an important role for the older cohorts. This means that unobserved factors, like social norms, have only been important for cohorts born before 1955. Social norms are an appealing explanation as sociological research on social norms and attitudes with respect to the combination of employment and family care responsibilities finds an almost identical development over the cohorts (SCP/CBS 2006). Furthermore, birth control may also have played a role as oral contraceptives became available in the years the cohorts born in the 1950s became mature (Goldin \& Katz 2002). The outcomes give us some important indications about the future prospects of the labour force participation of women. To make this point explicit, we construct long term scenarios. Apart from a basic scenario, we construct an 'emancipatory scenario', in which the combination of having paid work and raising children becomes more popular. It is not made explicit though whether this is the result of a policy change or due to a further change in social norms. The scenarios predict that female participation rates grow with a further 7 and 10\%-points, respectively. Using these scenarios, we estimate that the rising female participation rates compensate for about one third of the total fiscal sustainability gap in the Netherlands.

The remainder of this paper is organised as follows. Section 2 discusses some relevant literature on female labour supply. Section 3 discusses the data. Section 4 discusses the empirical strategy, and in particular the identification strategies used. Section 5 discusses the empirical findings, section 6 discusses future projections and the consequences for fiscal sustainability, and section 7 concludes. 


\section{Literature}

The empirical literature on female labour supply is broad, and varies from structural econometric modelling of financial incentives and life cycle decision making (for an overview, see, e.g., Blundell \& MaCurdy 1999) to more qualitative, historical analysis of changing life courses of women (see, for example, Goldin 2004, Goldin 2006). In between there is a quantitative literature that describes changes in labour market behaviour over time on the basis of panel data and repeated cross sections. We focus on two aspects that are important for our study. First, we discuss a number of empirical studies on a trend which is observed for several countries: the persistent increase of female labour force participation over time. Second, we discuss a number of empirical studies on changes in labour market behaviour due to the cyclical changes: the discouraged worker and added worker effect.

\subsection{The increase in female participation}

Several social scientists have studied the strong increase in the female labour force participation that has occurred in many western countries. We discuss some early and some recent studies for the UK and US, and subsequently we turn to the Netherlands.

Both the UK and the US experienced a strong increase in female labour market participation during the 20th century, and excellent census data made early studies possible. In both countries, economists were particularly interested in the question whether the increase in real wages could explain the increase in female participation. For the UK, Layard, Barton \& Zabalza (1980) used cross-section data from the UK Household Survey 1974 in order to estimate the wage elasticity, and concluded that wages explained about a third of the increase in female participation during the period 1973-1977. Joshi, Layard \& Owen (1985) turned to repeated census and survey data for 
the period 1850-1980 1 They isolate a clear cohort effect, and conclude that wages only explain a minor part of the increase in female participation. The authors offer some tentative explanations, such as falling prices of domestic services, changing fertility, and long-term changes in the roles women see for themselves in life.

On the basis of census data 1890-1980, Smith \& Ward (1985) conclude that rising real wages account for 60 percent of the total growth in the female labour force after 1950 in the US. Nevertheless they are not able to explain why participation did not increase earlier in history despite the fact that wages increase as well. They argue that other factors must have been important as well, and tentatively mention fertility, schooling, and changing attitudes towards women's work. Coleman \& Pencavel (1993) use census data and the Current Population Survey (CPS) for the period 19401988, and they report strong cohort effects in female participation. Female working hours did not change substantially over the different cohorts, and the authors conclude that gender differences in work behaviour are becoming less manifest in the US. Pencavel (1998) uses the CPS 1975-1994 and again finds that in particular participation has increased substantially, while working hours have increased only slightly. He furthermore finds that in particular participation of high-skilled women has increased. Attanasio, Low \& Sanchez-Marcos (2004) use the PSID 1969-1998 to calibrate a life-cycle model for three generations of women. They conclude that in particular shifts in the costs of children relative to life time earnings are the most likely explanation for the strong increase in labour supply over the generations of women.

Several studies describe and analyse the increasing female labour market

\footnotetext{
${ }^{1}$ The special issue of the Journal of Labor Economics contained several articles that used repeated cross sections or repeated census data, including Smith \& Ward (1985) for the US, Hartog \& Theeuwes (1985) for the Netherlands, and Colombino \& De Stavola (1985) on Italy.
} 
participation that has and still is taking place in several countries. Examples are Beaudry \& Lemieux (1999), who use the Survey of Consumer Finances 1976-1884 to investigate the increase in Canada, Fitzenberger, Schnabel \& Wunderlich (2004), who use the Micro-Census 1976-1995 to investigate the increase in Germany, and Contreras, Puentes \& Bravo (2005), who use the Employment and Unemployment Survey 1957-1997 to investigate the increase in Greater Santiago, Chile.

The labour market participation of Dutch women started to increase from the 1970s onwards. Hartog \& Theeuwes (1985) used the Terms of Employment Survey 1979 to investigate the labour supply behaviour of women. They conclude that wage growth contributed substantially to the explanation of the increase in participation in the years after the Second World War. Note that at that time the female participation rate was about $37 \%$, which was clearly below the average of the OECD countries. In between 1979 and 1987 the female participation rate has seen an increase to about 50\%, and Groot \& Pott-Buter (1993) use the Supplementary Benefits Surveys 1979 and 1987 to investigate this increase. They conclude that changes in preferences must have induced the increase in female participation. Note that in these years real wage growth was low due to the economic crisis and the wage moderation policy. Female participation kept increasing during the 1990s, and Coervers \& Golsteyn (2003) use the Socio-Economic Panel 1994-1999 to investigate this increase. Like the previous authors, they find that preferences must have played an important role, while again wage growth was relatively low due to wage moderation. Henkens, Grift \& Siegers (2002) use the Housing Demand Surveys 1989/90 and 1998/99 to compare married and cohabiting women, and they find that in particular participation of married women has increased.

So, while some economists conclude that real wage growth played an important role for the increase in female participation in the UK and the 
US, conclusions on the Netherlands seem to direct more towards changes in preferences. This tendency is adressed by Vendrik (2001), who employs the theory of social custom of Akerlof (1980) to describe the potential importance of evolving norms within society for the increase in labour market participation of women.

\subsection{The discouraged and added worker effect}

Every year, many accidental events affect the labour market. Many of these events are like random draws that are unrelated to the characteristics of the labour force and also unrelated to each other. The business cycle however leads to a correlation over time. In particular, for the labour force participation this may take place in two ways: through the 'discouraged worker effect' and through the 'added worker effect'.

The discouraged worker hypothesis states that potential participants decide to withdraw themselves from the labour market because they believe that their chances to find suitable employment are bad because of an unfavourable labour market situation. Although economists believe in such an effect already for some time, empirical researchers faced a hard time in convincingly proving its existence (Benati 2001). Nevertheless, recent evidence shows that such an effect is likely to exist. Time series analysis for several countries (Tachibanaki \& Sakurai 1991, Gregg 1994, Darby, Hart \& Vecchi 2001) shows that participation and some other measures for labour market behaviour display a clear pro-cyclical pattern. Furthermore, van Ham, Mulder \& Hooimeijer (2001) and van Ham \& Büchel (2004) use geographical variation in the Netherlands and Germany, respectively, and find that local labour market conditions do affect labour market behaviour.

The added worker hypothesis (sometimes called 'additional worker hypothesis') states that the unemployment of the husband induces the wife to participate. As unemployment is high during economic downturns, it 
counteracts the discouraged worker effect on the macro-economic level. The existence of the effect is however questionable, and may at best be small. No evidence for an added worker effect is found on the basis of the PSID 1976 and 1982 (Maloney 1991, Maloney 1997). On the basis of displaced workers in the PSID 1968-1992, Stephens (2001) finds that the long-run increase in the wife's labour supply accounts for about $25 \%$ of the husband's lost income. In addition he has found that wives of high earning husbands are more likely to generate an added worker effect than wives of lower earning husbands. On the basis of the European Panel Household Survey 19941996, Prieto-Rodriguez \& Podriguez-Gutierrez (2000) find that only in a few countries the participation of wives is related to the husbands' labour market status. The evidence in favour of the added worker effect is therefore not overwhelming, and at best there may be a small effect in some countries.

\section{Data}

The data used in this paper are from the Dutch Labour Force Survey 19922004 (DLFS; in Dutch 'Enqute Beroepsbevolking'). The DLFS is a survey conducted among persons living in the Netherlands, with the exception of those living in institutions like nursing homes and prisons. Every year, a random sample of about $1 \%$ of the Dutch population aged 15 and older is interviewed. A new random sample is drawn in every year, so that we do not observe multiple observations for a given individual. The DLFS collects information on the individual labour market situation and on individual and household characteristics.

From 1992 onwards, definitions and methods in the DLFS have changed radically, which means that prior years could not be used in our analysis. In the new definition, only persons working at least 12 hours a week and persons actively searching for a job of at least 12 hours a week belong to the labour force. We use this definition of the gross participation rate, as it is 
the official definition used in the Netherlands.

The resulting data set contains 516,298 observations of women, which amounts to nearly 40,000 observations per year. The oldest cohort was born in 1925, and the youngest cohort was born in 1986 (table 1). Each cohort (age group) contains about 8,000 $(10,000)$ individuals. The number of observations is somewhat lower for the oldest age categories and cohorts due to mortality. Furthermore, note that the smallest category ('Other household member') still counts more than 5,000 observations. More than half the sample has no children living at home. About one out of eight women have at least one child younger than 4 years old living at home. Note that these and other variables on children in the household are not mutually exclusive.

[insert Table 1 here]

The observed participation rates by cohort and age are shown in figure 1 . Participation rates for the youngest ages are increasing steeply, while from age 25 on a gradually decreasing pattern appears. From the overlapping segments at a given age it can be read that increments of about 10\%-points between subsequent five-year cohorts are not uncommon. The 'jumps' are combined cohort and time effects. Obviously, age effects play a role as well in explaining the observed pattern. In the following sections we will seek to disentangle these effects.

[insert Figure 1 here]

\section{Empirical strategy}

In this section, we specify the statistical model that is used to estimate the determinants of female labour force participation. Indicating individual $i$ and (discrete) time $t$ by corresponding subscripts, our model specifies the 
propensity to participate in the labour market as:

$$
p_{i t}^{*}=\beta_{0}+\beta_{1} x_{i t}+g_{a}\left(a_{i t} \mid \theta_{a}\right)+g_{c}\left(c_{i} \mid \theta_{c}\right)+g_{t}\left(t \mid \theta_{t}\right)+\epsilon_{i t},
$$

where $x_{i t}$ is a vector of control variables, $a_{i t}, c_{i}$, and $t$ are age, cohort, and year effects, respectively, and corresponding transformation functions are denoted by $g$. Now, we specify the probability of observing individual $i$ participating in the labour market at time $t$ as a binary Logit (i.e. we assume that $\epsilon_{i t}$ follows a standard logistic distribution):

$$
\begin{aligned}
& \operatorname{Pr}\left\{p_{i t}=1 \mid x_{i t}, a_{i t}, c_{i}, t\right\}= \\
& \frac{\exp \left(\beta_{0}+\beta_{1} x_{i t}+g_{a}\left(a_{i t} \mid \theta_{a}\right)+g_{c}\left(c_{i} \mid \theta_{c}\right)+g_{t}\left(t \mid \theta_{t}\right)\right)}{1+\exp \left(\beta_{0}+\beta_{1} x_{i t}+g_{a}\left(a_{i t} \mid \theta_{a}\right)+g_{c}\left(c_{i} \mid \theta_{c}\right)+g_{t}\left(t \mid \theta_{t}\right)\right)},
\end{aligned}
$$

where $p_{i t}$ equals unity if individual $i$ participates at time $t$, and zero otherwise.

A well-known complication in (1) is that not all the parameters can be identified whenever all transformation functions $g_{a}, g_{c}$, and $g_{t}$ contain a (parametrised) linear term. The reason is that the following identity holds for any individual $i$ at time $t$ :

$$
c_{i}+a_{i t}=t,
$$

i.e. whenever both the birth year and the age of an individual are known, then the current year is known as well. Or, whenever two terms in (3) are known then the third is known as well. Several ways have been suggested to circumvent this identification problem. Probably the most straightforward strategy is to omit an entire $g$-function altogether, and replace it by some other variable, or set of variables, which are thought to represent the concerning effect. This procedure is called the proxy variable approach, and is e.g. applied in Portrait, Alessie \& Deeg (2002). In the current case, we will include a variable which represents the 'period effects' of the female participation rate and omit $g_{t}$. For instance, if such period effects are thought 
to be the consequence mainly of discouraged and added worker effects (see section 2.2), then a logical proxy variable would be the unemployment rate. In a second approach, the 'functional form approach', it is assumed that the $g$-functions follow a prespecified functional form for which the model parameters in (1) are identified. This is e.g. the case when one transformation function is a logarithmic function, $g(x)=\delta \ln x$. However, if the $g$-functions are chosen such that not all parameters are identified, then one additional restriction of the form

$$
H\left(g_{a}^{\prime}(0), g_{c}^{\prime}(0), g_{t}^{\prime}(0)\right)=0
$$

needs to be imposed. Here, the prime indicates the first derivative, and it is assumed that the $g$-functions are differentiable and exist in 0. For instance, in case the $g$-functions are higher order polynomials, setting the function $H(x, y, z)=y$ equal to zero as in (4) imposes that no linear cohort effect is present. Such a strategy was e.g. used in Fitzenberger et al. (2004). The functional form approach is acceptable in case there exist strong a priori reasons to believe that one of the transformation functions does not contain a linear term. If this is however not the case, then the imposed restriction in (4) may severely impact estimation results.

A final approach is to define the $g$-functions as step functions of the form $g(x)=\sum_{k=1}^{K} \alpha_{k} 1\left\{x=x_{k}\right\}$, where $K$ is the total number of categories for variable $x$, and $1\{A\}$ is the indicator function for event $A$. Additional restrictions on the parameters $\left(\alpha_{k}\right)$ are imposed in order to achieve identification. This widely used approach, which was first introduced by Mason, Mason, Winsborough \& Poole (1973), was however criticised for the arbitrariness of the imposed restrictions, and the fact that it is not testable whether the restrictions are valid. Moreover, the dummy variables are considered to be a crude measure for the underlying factors of real interest and fail to address causality between the underlying variables and the endogenous variable (Heckman \& Robb 1985). We will therefore not apply this approach 
in the current paper ${ }^{2}$

Having estimated a model specification as described above, we may decompose the growth in female participation for different years. Denoting the probability in (2) by $q_{t}$ (and omitting the individual subscript), we compute the marginal effect of variable $x_{j}$ as

$$
\frac{\partial q_{t}}{\partial x_{j}}=q_{t}\left(1-q_{t}\right) \beta_{j}
$$

and approximate the change in participation as a result of a change in factor $x_{j}$ at time $t$ by

$$
e_{j t}=\bar{q}_{t}\left(1-\bar{q}_{t}\right) \beta_{j} \Delta \bar{x}_{j t}
$$

where $\bar{q}_{t}$ denotes the predicted probability that an average female is participating at time $t$, and $\bar{x}_{j t}$ denotes the average value of covariate $j$ at time $t$. Using the Delta method we may estimate standard errors as follows:

$$
\text { s.e. }\left(e_{j t}\right)=\sqrt{\operatorname{diag}\left[\left(\partial e_{j t} / \partial \beta\right) \Sigma_{\beta}\left(\partial e_{j t} / \partial \beta\right)^{\prime}\right]}
$$

where $\Sigma_{\beta}$ is the estimated covariance matrix for the parameter vector $\beta$, and $\partial e_{j t} / \partial \beta$ is a row vector containing the partial derivatives of $e_{j t}$ with respect to all elements in the parameter vector:

$$
\begin{aligned}
& \frac{\partial e_{j t}}{\partial \beta_{i}}=e_{j t} \bar{x}_{i t}\left(1-2 \bar{q}_{t}\right) \quad(\text { for all } i \neq j) \\
& \frac{\partial e_{j t}}{\partial \beta_{j}}=e_{j t}\left(\bar{x}_{j t}\left(1-2 \bar{q}_{t}\right)+1 / \beta_{j}\right)
\end{aligned}
$$

We will employ these formulas in the next section when making a decomposition of the aggregate growth in female labour force participation during the period 1992-2004.

\footnotetext{
${ }^{2}$ We experimented with this methodology and indeed found the results to be sensitive for the identification restrictions.
} 


\section{Estimation}

This section discusses the estimation results of the specifications explained in the previous section. The coefficients reported in table 2 represent the impact of a variable on the probability of participation. For example, the positive coefficients for cohabiting women imply that this category is more likely to participate on the labour market than married women.

The first specification uses the proxy variable approach, where period effects are proxied by the variable 'delayed unemployment rate' (Model I). The unemployment rate typically indicates to which extent an individual is encouraged or discouraged to participate in the labour market. This may be either through the discouraged worker effect or through the added worker effect (see section 2.2). We assume that the labour market situation of a woman with a certain level of education is determined by the average unemployment rate of individuals with that particular level of education. Note that we have chosen the one-year delayed unemployment rate because non-participating females are not likely to have up-to-date information on their labour market prospects. Furthermore, note that the increase in real wages may be another important time trend. We control for educational attainment, which means that we do take into account the increase in real wages due to an increase in the level of education. However, we are not able to correct for the real wage increase given the level of education.

The estimation results show that women are less likely to participate when the level of unemployment is high, implying that the discouraged worker effect is stronger than the added worker effect. This is in line with what was suggested in the empirical literature discussed in section 2.2. Furthermore, being married is negatively related to the labour force participation of women. Women who are part of an unmarried couple have a relatively high probability to participate. Before turning to the results for the alternative specification (Model II) we proceed with a further interpretation of the 
estimation results for Model I.

[insert Table 2 here]

The presence of children has a negative effect on female participation, and this negative impact is particularly strong in the presence of young children. Participation goes up once the youngest child attends primary school, and once again when it attends secondary school (in the Netherlands this usually occurs at the ages of 4 and 12, respectively). The negative participation effect of having children increases in magnitude when more children are involved. The presence of major children also has a negative effect, but this is much smaller in magnitude. In addition, we find specific effects for single women. The presence of children younger than 18 lowers the probability of participation for single women. On the other hand, the presence of major children increases the participation rate of single women. We also find that highly educated women with minor children are more likely to participate than other women.

From the interaction terms between having children and time (shown in appendix A) we learn that the negative effect of raising minor children has decreased importantly between 1992 and 2004 (see also figure 2). The decrease may be the result of the increase in the availability and affordability of child care facilities, which is partly the result of higher subsidies from the government. Another explanation may be a change in attitudes towards the combination of paid employment and caring for children 3 Note that the reported coefficients should not be interpreted as causal effects, as both participation and children (as far as it is a choice) may be the result of a simultaneous decision. Therefore, the causal effect of children on participation may be smaller in magnitude than the point estimates reported 4 As a

\footnotetext{
${ }^{3}$ Note that compared to other countries, Dutch women traditionally have a rather negative attitude towards the use of child care facilities (Kremer 2005).

${ }^{4}$ It has been noted in the literature that, apart from a reversed causality problem,
} 
benchmark, we have also included in figure 2 the predicted participation rate for the average woman with no children. It can be seen that the participation rate of women with children aged 12 and above is rapidly converging to that of women without any children. For women with children under 12 years of age the gap still remains substantial.

[insert Figure 2 here]

A high level of education results in a high probability of participation. As we do not observe wage rates, this variable principally serves as a proxy for the former. The level of education of the partner also plays a role in the decision to participate in the labour market. In figure 3 the results of the combinations of the education for a woman and her partner are summarized. We have computed the probabilities of participation for an 'average' woman with different combinations of the level of education for her and her partner. With an 'average' woman we mean that for all characteristics the mean of the data is taken, except for the educational variables under consideration. A higher level of education of the partner has a positive effect on females' participation rates. However, when the partner is tertiary educated the probability of participation decreases a bit (compared to higher secondary education).

[insert Figure 3 here]

The estimated unobserved cohort and age effects are shown in figures 4 and 5. In these figures, we have computed the probabilities in (2), setting explanatory variables to their sample average values except for the cohort and age dummy variables. Note that each birth year / age is represented by a unique dummy variable, implying that both cohort and age effects are estimates of the effect of children on the participation decision often suffer from omitted variable bias as having children is typically correlated with unobserved taste factors (Nakamura \& Nakamura 1994). 
estimated with a maximum degree of flexibility. From the first figure it can be seen that the unobserved cohort effect has been almost linearly increasing over the cohorts born between 1925 and 1955. This means that the variables included in our model cannot 'explain' the entire participation growth for these cohorts, and hence, other forces are at work. On the other hand, the unobserved cohort effect remains remarkably stable for cohorts born after 1955, implying that the included variables on educational attainment, children, and household situation (and interactions) are able to 'explain' increasing participation rates for younger cohorts.

[insert Figure 4 here]

From figure 5, it can be seen that unobserved age effects increase until the age of 25, are more or less constant between ages 25 and 40, and decrease from the age of 40 years. Comparing this figure with figure 1, we conclude that the female 'motherhood dip' around the age of 30 is indeed explained by the presence of children. It is however remarkable that the age profile already starts decreasing around the age of 40 years. Complementarity of leisure time with that of an older partner can be regarded as an explanation for relatively early retirement of women (see, e.g., Hurd 1990). It may also be the case that some delayed effect is taking place. Women who have lost attachment to the labour market while taking care of young children may find it difficult to reignite their careers, and in the end decide to withdraw from the labour market altogether. As our model specification does not take account of a delayed effect of having children, this effect is part of the unobserved age effect.

[insert Figure 5 here]

In figure 6, we compare the growth of female participation rates predicted by the model with observed growth. For most years the predicted 
growth rates are quite accurate; for 1993, 1998, and 2000 the model overestimates growth by more than one \%-point, and for 1994 and 2004 the model underestimates growth by nearly a \%-point.

[insert Figure 6here]

In table 2 we also report results for a second specification, which is based on the functional form approach (Model II). This specification postulates that cohort effects follow a logarithmic pattern over time. An attractive feature of this functional form is that its derivative tends to zero as time passes by, implying that the increase in participation rates over subsequent cohorts becomes smaller and smaller, which is expected. Moreover, results from the previous specification suggest that this functional form is not a heavy assumption. As can be read from the table, parameter estimates for both models are mostly qualitatively the same. Results on the estimated age and cohort effects are similar as well, except for the fact that the cohort effect is of course much more smooth compared to the effect in figure 4 as a result of the functional form assumption.

The decomposition of participation growth for the years 1992-2004 based on Model I is reported in table 3 (computed cf. (5)). The total change in the participation rate amounts to 13\%-points over the period 1992-2004. It can be seen that nearly half of this effect has to do with the household situation. In particular, the participation decision has become less sensitive for raising children, i.e. women with children decide to participate in the labour market more often. This is precisely the effect shown in figure 2, A second household effect predicted by the model results from the fact that the share of single women is increasing, and those who do live together choose to marry less often. According to the model, both these categories show higher participation rates than married females.

[insert Table 3 here] 
The second most important factor explaining the increasing participation rates are the unobserved cohort effects, which account for one quarter of total growth. During the period 1992-2004 many women from the pre-1955 generations retired from the labour market, while at the same time younger cohorts with relatively high unobserved cohort effects entered the labour market. According to our model, this composition effect led to an increase in the overall female participation rate by $3.3 \%$-points.

Third, increasing levels of education account for about one sixth of total growth, and an encouraged worker effect of one eighth of the total growth is found. The latter is not surprising, as the economy was booming during most of the period under consideration. Other effects, like the education of the partner, are less relevant in explaining participation growth.

In terms of statistical significance at the common $5 \%$ level, we may conclude that the demographic composition of households, education, changing effect of having children, unobserved cohort effects, and a cyclical encouraged worker effect have all contributed to the growth of the participation rate during the period.

Perhaps somewhat suprisingly, the age composition does not have a significant effect on the development of the participation rate. This may however change in the future, when the share of elderly in the population will increase further. To illustrate this, we have depicted the development of the age effect over time in figure 7. It also appears from the figure that the impact of the unobserved cohort effects decreases over time. This finding is particularly important for the future development of female labour force participation.

[insert Figure 7 here] 


\section{Projected growth in two scenarios}

In this section, we make a projection for the coming decades by substituting future projections for variables and unobserved age and cohort effects into Model I, with the parameter values fixed at the point estimates reported in table 2 and in appendix A. Projections for all household variables and variables related to children are based on the long-term forecasts of Statistics Netherlands (van Agtmaal-Wobma \& van Duin 2007). The demographic (long-term) projection is also taken from Statistics Netherlands (de Jong 2005). Unemployment is fixed at the estimated equilibrium rate of $4.4 \%$ (CPB 2006). A short overview of the projections for the underlying variables is provided in table 4 .

$$
\text { [insert Table } 4 \text { here] }
$$

The fraction of women who live in a household without children increases with $4 \%$-points. However, not much change is expected for the number of children in households which do have at least one child. According to the forecast, there will only be a small decrease in the number of households with three children or more, and a correspondingly small increase in the fraction of households with two children. Furthermore, there will be more single women, more cohabiting women, and less married women. The fraction of higher educated females rises from 25 to $34 \%$, and for male partners the same share of highly educated is achieved. This increase goes together with a decrease in the fractions of primary and lower secondary educated individuals, with both groups showing a similar decrease by about 4\%-points.

One of the most crucial parameters in the future projection is the development over time of the effect of having children. As the estimation results hardly provide any clue where this trend will stop (viz. figure 2), we have to make a rather arbitrary assumption on this. In order to investigate the impact of such an assumption, we construct two different scenarios. 
In the basic scenario we assume that there are no further developments in this variable, i.e. the child effect remains constant at the 2004 level. In the alternative scenario, we assume that the remaining growth (after the year 2004) equals the growth during the period 1998-2004. An important argument for not postulating too large a growth is that child care facilities - especially government subsidies for families with children - are currently already at a high level (Jongen 2008). While the introduction of these facilities has contributed to the past growth of the female participation rate, it seems unlikely that it will continue to do so. We postulate that the main driver of the increasing child effect may be a more favourable attitude of women towards the combination of paid work and care for children. This may, for example, be the result of dynamics in these atitudes as nowadays non-employed women with children see more and more women with children that are employed.

Finally, we presume that both the unobserved cohort and age effects remain constant for future generations. The former was strongly suggested by the estimation results shown in figure 4, which shows that the unobserved cohort effect has been rather constant since the generation born around 1955 . The latter implies that unobserved age effects remain the same for future generations. Changes in the age profile are therefore assumed to occur only as a result of changes in exogeneous variables like the presence of children. Note that there may of course still be a residual age effect at the aggregate level, due to a changing demographic composition. Likewise, an aggregate cohort effect is expected when the generations born before 1955 will be replaced by younger generations.

The resulting projected growth of the female participation rate is shown in table 5. The household situation, the fact that there will be less households with children, the increasing level of education, and a structurally lower unemployment rate all help to increase the participation rate from 
2004 on. The effect of each of these factors is about 1.6\%-points. These four factors are thus equally important for the future growth of female labour supply in the basic scenario.

[insert Table 5 here]

The aggregate unobserved age effect is negative as a result of relatively more elderly females with low participation rates. The aggregate residual cohort effect is positive since a part of the pre-1955 cohorts with relatively low participation rates will still be replaced by younger cohorts. As both effects have about the same size, they cancel out. In sum, the projected growth in the basic scenario amounts to $7 \%$-points, which equals about half of the growth during the period 1992-2004.

In the 'emancipatory scenario', there still is a large effect of changing attititudes towards the combination of paid work and family responsibitities, which makes total participation growth equal to nearly $10 \%$-points.

We have also checked the sensitivity of the basic scenario with respect to the education projection (not reported in the table). An important difference with the child/time-effect is that the education variables cause less uncertainty as a result of 'natural bounds' (e.g. it seems unlikely that the share of highly educated will exceed one half). For instance, if the growth in higher education participation is only half as great as desribed above, then total participation growth in the is lowered by just one \%-point (in both scenarios).

It is well-known that the current government budgets of many industrialised countries are not sustainable in the light of the ageing populations in these countries. The main reason for this is that many social arrangements, like e.g. health care, social insurance, and pensions, are predominantly financed on a pay-as-you-go basis (PAYG), while the elderly relatively often make use of these arrangements. Of course, the extent to which these 
PAYG arrangements imply an unsustainable fiscal regime depends on many country-specific parameters (for a comparison among different European countries, see Economic Policy Committee 2006). How does a change in the participation rate impact fiscal sustainability? First, a change in the participation rate affects employment, as new participants in the labour market will largely find their way to paid work. This is possibly the case after an adjustment has been made in the wage rate in order to reach a new equilibrium. Second, employment boosts economic growth, and this leads to an increase in government revenues. For the Netherlands, it has been calculated that a $2 \%$-points increase in the labour force participation of women implies an improvement of the fiscal sustainability by $0.3 \%$-points of GDP, keeping other factors fixed (van Ewijk et al. 2006) 5 Hence, if we take the projected remaining growth in the female labour participation rate of $7 \%$-points that was calculated in the previous subsection, it is expected that the fiscal sustainability is improved by about 1\%-point of GDP. In the 'emancipatory scenario' this is increased to $1.5 \%$ of GDP. Compared to the entire structural deficit, this implies that about one third is alleviated as a direct result of the increasing female participation rate ${ }^{6}$

\footnotetext{
${ }^{5}$ This computation takes into account part-time work, structural unemployment, and the fact that some government expenditures show a negative relation with GDP. It is noted that the newly participating women are assumed to work on average at the same part-time basis as other female participants (Bosch, Deelen \& Euwals 2008). It is also implicitly assumed that male participation rates are not affected by the increasing participation rates of their female partners.

${ }^{6}$ The sustainability gap is estimated at $2.6 \%$ of GDP by van Ewijk et al. (2006), assuming an increase in female participation of $5.2 \%$. Without this increase the sustainability gap would have been $3.4 \%$.
} 


\section{Conclusion and discussion}

In the Netherlands, the female participation rate has increased considerably over the last decades. A further increase will help to alleviate the problem of fiscal sustainability due to the ageing of the society. Which factors have played a role in the increase of the female participation rate between 1992 and 2004, and which further increase may we reasonably expect in the next decades? In order to answer these questions, we estimate a binary ageperiod-cohort model for the participation of women born between 1925 and 1986 on the basis of the Dutch Labour Force Survey 1992-2004. We use demographic forecasts of Statistics Netherlands to make an educated guess for the future development of female participation rates.

The estimation results indicate that the female participation rate is higher when the labour market is relatively tight. Between 1992 and 2004 the business cycle caused an increase in the female participation rate by nearly $2 \%$-points. Further, with regard to the household situation, single and cohabiting women have a relatively high probability to participate, while women with children have a relatively low probability to participate. The effect of having children is different for singles and for women part of a couple. Between 1992 and 2004 participation has become less sensitive for the presence of children, and this has played an important role in the increase of the participation rate. During the period under consideration, the availability and affordability of child care facilities improved substantially, and this may explain an important part of this effect. Furthermore, the increase in the education level between 1992 and 2004 has caused one sixth of the total increment in the female participation rate between 1992 and 2004.

Changes in unobserved cohort effects are very important for the cohorts born between 1935 and 1955. These effects account for about one quarter of the total increase in the female participation rate between 1992 and 2004. The estimated unobserved cohort effects are rather constant for the gener- 
ations born after 1955. Note that the unobserved cohort effects should be interpreted with care as they may pick up time trends that we did not correct for. An obvious candidate for such a time trend would be the increase in real wages per level of education as it may have encouraged women to participate in the labour market. This may explain part of the increase in participation over the successive cohorts. It cannot explain, however, the stable cohort effect for the generations borm after 1955 .

Although our research does not explicitly address the role of social norms and attitudes towards paid employment, it is conceivable they play a role in explaining the development of participation over successive cohorts. The reason is that sociological research on social norms and attitudes with respect to the combination of employment and family care responsibilities finds a development over the cohorts which is practically identical to the development we find for participation. On the basis of repeated surveys from 1970 to 2004, SCP/CBS (2006) find that the generations born before the 1950s found it less and less problematic that women with children are employed, while the more recent generations of the 1970s and 1980s nowadays have about the same opinion as the generation born in the 1950s. The developments of participation over generations has been addressed in the international literature as well. Fernandez (2007) confronts a model of culture and intergenerational learning with the increase in US female participation. She concludes that culture can explain the particular pattern of the increase in participation. And there is evidence for the US that birth control has played a role as well. Goldin \& Katz (2002) find that oral contraceptives, which became available in the years the generations born in the 1950s became mature, did affect family formation and the careers of women of this generation.

Using our estimation results, we have given some indication of the future prospects of female labour force participation. The female participation is 
likely to increase at a much lower rate, in particular as we find no indications that social norms with regard to paid employment will evolve again. In the two scenarios we construct, the female participation rate increases by 7 and 10\%-points, respectively, depending on the assumption made on the evolvement of attitudes towards the combination of paid work and children. A simple calculation shows that this increment alleviates the structural fiscal deficit caused by ageing of the population by 1.0 to 1.5\%-points of GDP.

\section{References}

Aaberge, R., Colombino, U. \& Holmøy, E. (2004), Population ageing and fiscal sustainability: An integrated micro-macro analysis of required tax changes. Discussion Paper 367, Statistics Norway.

Akerlof, G. (1980), 'A theory of social custom, of which unemployment may be one consequence', Quarterly Journal of Economics 94, 749-775.

Apps, P. (1991), 'Tax reform, population ageing and the changing labour supply behaviour of married women', Journal of Population Economics 4, 201-216.

Attanasio, O., Low, H. \& Sanchez-Marcos, V. (2004), Explaining changes in female labour supply in a life-cycle model. Cambridge Working Papers in Economics 0451.

Beaudry, P. \& Lemieux, T. (1999), 'Evolution of the female labour force participation rate in Canada 1976-1994: A cohort analysis', Canadian Business Economics pp. 1-14.

Benati, L. (2001), 'Some empirical evidence of the discouraged worker effect', Economics Letters 70, 387-395. 
Blundell, R. \& MaCurdy, T. (1999), Labour supply: A review of alternative approaches, in O. Ashenfelter \& D. Card, eds, 'Handbook of Labor Economics, vol. 3A', North-Holland, pp. 1559-1695.

Bosch, N., Deelen, A. \& Euwals, R. (2008), Is part-time employment here to stay? Evidence from the Dutch Labour Force Survey 1992-2005. CPB Discussion Paper (forthcoming).

Coervers, F. \& Golsteyn, B. (2003), Changes in women's willingness to work in a tightening labour market: the impact of preferences, wages and individual characteristics. ROA Research Memorandum 2003/5E.

Coleman, M. \& Pencavel, J. (1993), 'Trends in market work behavior of women since 1940', Industrial and Labor Relations Review 46, 653-676.

Colombino, U. \& De Stavola, B. (1985), 'A model of female labor supply in Italy using cohort data', Journal of Labor Economics 3, S275-S292.

Contreras, D., Puentes, E. \& Bravo, D. (2005), 'Female labour force participation in Greater Santiago, Chile: 1957-1997. A syntethic cohort analysis', Journal of International Development 17, 169-186.

Cournède, B. \& Gonand, F. (2006), 'Restoring fiscal sustainability in the Euro Area: raise taxes or curb spending?', Economics Department Working Paper No. 520, OECD.

CPB (2006), 'Het groeipotentieel van de Nederlandse economie tot 2011', CPB Document 117.

Darby, J., Hart, R. \& Vecchi, M. (2001), 'Labour force participation and the business cycle: A Comparative Analysis of France, Japan, Sweden, and the United States', Japan and the World Economy 13, 113-133.

de Jong, A. (2005), 'Bevolkingsprognose 2004-2050: maximaal 17 miljoen inwoners', Bevolkingstrends 53(1), 12-18. 
Economic Policy Committee (2006), The impact of ageing on public expenditure: Projections for the EU25 member states on pensions, health care, long-term care, education, and unemployment transfers (20042050), European economy, special report no. 1, European Commission, Directorate-General for Economic and Financial Affairs, Brussels.

Fernandez, R. (2007), 'Culture as learning: the evolution of female labour force participation over a century', CEPR Discussion Paper, No. 6451.

Fitzenberger, B., Schnabel, R. \& Wunderlich, G. (2004), 'The gender gap in labor market participation and employment: A cohort analysis for West Germany', Journal of Population Economics 17(1), 83-116.

Goldin, C. (2004), 'The long road to the fast track: Career and family', The Annals of the American Academy of Political and Social Science 596, $20-35$.

Goldin, C. (2006), 'The 'quiet revolution' that transformed women's employment, education, and family', American Economic Review, Papers and Proceedings 96, 1-21.

Goldin, C. \& Katz, L. (2002), 'The power of the pill: Oral contraceptives and women's and marriage decisions', Journal of Political Economy 10, $730-770$.

Gregg, P. (1994), 'Out for the count: a social scientist's analysis of unemployment statistics in the UK', Journal of the Royal Statistical Society Series A 157, 253-270.

Groot, W. \& Pott-Buter, H. (1993), 'Why married women's labor supply in the Netherlands has increased?', De Economist 141, 238-255.

Hartog, J. \& Theeuwes, J. (1985), 'The emergence of the working wife in Holland', Journal of Labor Economics 3, S235-S255. 
Heckman, J. \& Robb, R. (1985), Using longitudinal data to estimate age, period, and cohort effects in earnings equations, in W. Mason \& S. Fienberg, eds, 'Cohort Analysis in Social Research: Beyond the Identification Problem', Springer-Verlag, New York, pp. 137-150.

Henkens, K., Grift, Y. \& Siegers, J. (2002), 'Changes in female labour supply in the Netherlands 1989-1998: The case of married and cohabiting women', European Journal of Population 18, 39-57.

Hurd, M. (1990), The joint retirement decision of husbands and wives, in D. Wise, ed., 'Issues in the Economics of Aging', The University of Chicago Press, pp. 231-254.

Jongen, E. (2008), Child care subsidies revisited. CPB Document (forthcoming).

Joshi, H., Layard, R. \& Owen, S. (1985), 'Why are more women working in Britain?', Journal of Labor Economics 3, S147-S175.

Kremer, M. (2005), How welfare states care: culture, gender and citizenship in Europe., PhD thesis, Utrecht University.

Layard, R., Barton, M. \& Zabalza, A. (1980), 'Married women's participation and hours', Economica 47, 51-72.

Maloney, T. (1991), 'Unobserved variables and the elusive added worker effect', Economica 58, 173-187.

Maloney, T. (1997), 'Employment constraints and the labor supply of married women: A reexamination of the added worker effect', Journal of Human Resources 22, 51-61.

Mason, K., Mason, W., Winsborough, H. \& Poole, W. (1973), 'Some methodological issues in cohort analysis of archival data', American Sociological Review 38, 242-258. 
Nakamura, A. \& Nakamura, M. (1994), 'Predicting female labor supply: effects of children and recent work experience', Journal of Human Resources $\mathbf{2 9}, 304-327$.

Pencavel, J. (1998), 'The market work behavior and wages of women: 19751994', Journal of Human Resources 33, 771-804.

Portrait, F., Alessie, R. \& Deeg, D. (2002), Disentangling the age, period and cohort effects using a modeling approach, Discussion Paper TI 2002-120/3, Tinbergen Institute.

Prieto-Rodriguez, J. \& Podriguez-Gutierrez, C. (2000), 'The added worker effect in the Spanish case', Applied Economics 31, 1917-1925.

Roeger, W. (2002), 'Ageing and pensions in Europe', mimeo, European Commission, Directorate General for Economic And Financial Affairs.

Rother, P., Catenaro, M. \& Schwab, G. (2002), 'Ageing and pensions in the Euro area; survey and projection results', mimeo, European Central Bank.

SCP/CBS (2006), 'Emancipatiemonitor 2006', SCP publication 2006/22.

Smith, J. \& Ward, M. (1985), 'Time-series growth in the female labor force', Journal of Labor Economics 3, S59-S90.

Stephens, M. (2001), Worker displacement and the added worker effect. NBER Working Paper 8260.

Tachibanaki, T. \& Sakurai, K. (1991), 'Labour supply and unemployment in Japan', European Economic Review 35, 1575-1587.

van Agtmaal-Wobma, E. \& van Duin, C. (2007), 'Huishoudensprognose 2006-2050: belangrijkste uitkomsten', Bevolkingstrends 55(2), 53-59. 
van Ewijk, C., Draper, D., ter Rele, H. \& Westerhout, E. (2006), Ageing and the sustainability of Dutch public finances, CPB Netherlands Bureau for Economic Policy Analysis.

van Ham, M. \& Büchel, F. (2004), 'Females' willingness to work and the discouragement effect of a poor local childcare provision', Applied Economics Quarterly 4, 363-377.

van Ham, M., Mulder, C. \& Hooimeijer, P. (2001), 'Local underemployment and the discouraged worker effect', Urban Studies 38, 1733-1751.

Vendrik, M. (2001), 'Dynamics of a household norm in female labour supply', Journal of Economic Dynamics and Control 27, 823-841.

\section{A Extended estimation results}

[insert Table 6 here]

[insert Table 7 here]

[insert Table 8 here] 
Tables and figures 
Table 1: Summary statistics

\begin{tabular}{|c|c|c|c|c|}
\hline & Mean & Min. & Max. & \# Obs. \\
\hline \multicolumn{5}{|l|}{ Position in household } \\
\hline Married & 0.60 & 0 & 1 & 516298 \\
\hline Cohabiting, been married & 0.02 & 0 & 1 & 516298 \\
\hline Cohabiting, never been married & 0.11 & 0 & 1 & 516298 \\
\hline Single, been married & 0.10 & 0 & 1 & 516298 \\
\hline Single, never been married & 0.09 & 0 & 1 & 516298 \\
\hline Living with parents & 0.07 & 0 & 1 & 516298 \\
\hline Other & 0.01 & 0 & 1 & 516298 \\
\hline \multicolumn{5}{|l|}{ Children } \\
\hline No children & 0.57 & 0 & 1 & 516298 \\
\hline Age youngest child 0-3 & 0.12 & 0 & 1 & 516298 \\
\hline Age youngest child 4-11 & 0.13 & 0 & 1 & 516298 \\
\hline Age youngest child $12-17$ & 0.09 & 0 & 1 & 516298 \\
\hline Two minor children & 0.16 & 0 & 1 & 516298 \\
\hline Three or more minor children & 0.07 & 0 & 1 & 516298 \\
\hline Both minor and major children & 0.05 & 0 & 1 & 516298 \\
\hline Only major children & 0.10 & 0 & 1 & 516298 \\
\hline \multicolumn{5}{|l|}{ Education woman ${ }^{\mathrm{a}}$} \\
\hline Primary & 0.14 & 0 & 1 & 516298 \\
\hline Lower secondary & 0.27 & 0 & 1 & 516298 \\
\hline Higher secondary & 0.39 & 0 & 1 & 516298 \\
\hline Tertairy & 0.20 & 0 & 1 & 516298 \\
\hline \multicolumn{5}{|l|}{ Education male partner ${ }^{a}$} \\
\hline Primary & 0.08 & 0 & 1 & 380686 \\
\hline Lower secondary & 0.15 & 0 & 1 & 380686 \\
\hline Higher secondary & 0.30 & 0 & 1 & 380686 \\
\hline Tertairy & 0.18 & 0 & 1 & 380686 \\
\hline Age & 41 & 18 & 67 & 516298 \\
\hline Period (year) & 1998 & 1992 & 2004 & 516298 \\
\hline Cohort (year of birth) & 1957 & 1925 & 1986 & 516298 \\
\hline
\end{tabular}

a The education levels are defined as follows: 'Primary' = no secondary education completed (just primary shool); 'Lower secondary' = lower vocational or general school completed (in Dutch: VMBO); 'Upper secondary' = advanced vocational or general school completed (in Dutch: MBO, HAVO, VWO); 'Tertiary' = academic or vocational colleges completed. 
Figure 1: Female participation rates by birth cohort and age (in \%)

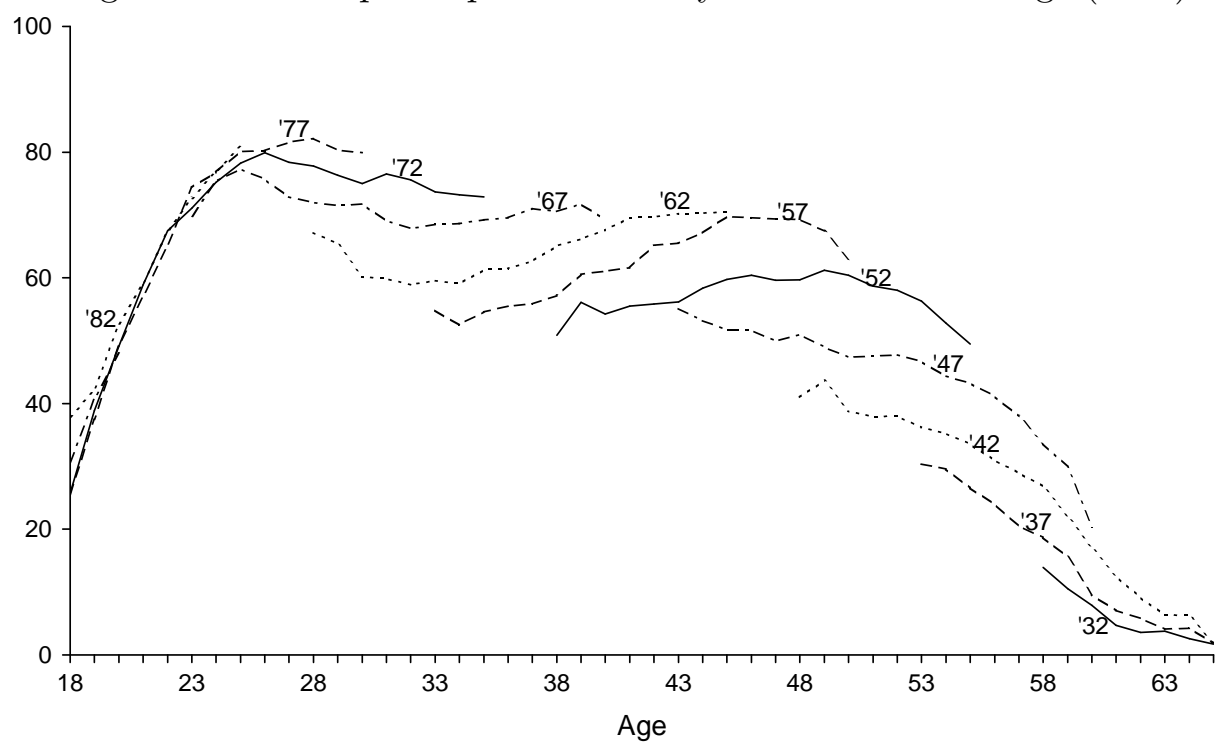

Note: Cohorts in 5-year groups, from cohort born in 1980-1984 (left in figure) to cohort born in 1930-1934 (right in figure) 
Table 2: Probability of participation in the labour markt, estimation results for model I (proxy variable approach) and model II (functional form approach $)^{\mathrm{a}}$

\begin{tabular}{|c|c|c|c|c|}
\hline & \multicolumn{2}{|c|}{ Model I } & \multicolumn{2}{|c|}{ Model II } \\
\hline & Est. & S.e. & Est. & S.e. \\
\hline \multicolumn{5}{|l|}{ Position in household } \\
\hline \multicolumn{5}{|l|}{ Married } \\
\hline Cohabiting, been married & 0.50 & 0.03 & 0.50 & 0.03 \\
\hline Cohabiting, never been married & 0.91 & 0.03 & 0.91 & 0.02 \\
\hline Single, been married & 0.25 & 0.05 & 0.25 & 0.04 \\
\hline Single, never been married & 0.07 & 0.06 & 0.07 & 0.04 \\
\hline Living with parents & 0.51 & 0.08 & 0.52 & 0.05 \\
\hline Other & 0.20 & 0.07 & 0.20 & 0.06 \\
\hline \multicolumn{5}{|l|}{ Children } \\
\hline \multicolumn{5}{|l|}{ No children } \\
\hline Age youngest child $0-3$ & -1.66 & 0.11 & -1.66 & 0.03 \\
\hline Age youngest child 4-11 & -1.27 & 0.11 & -1.26 & 0.03 \\
\hline Age youngest child $12-17$ & -0.81 & 0.11 & -0.79 & 0.03 \\
\hline Two minor children & -0.42 & 0.02 & -0.41 & 0.01 \\
\hline Three or more minor children & -0.89 & 0.02 & -0.89 & 0.01 \\
\hline Both minor and major children & -0.11 & 0.04 & -0.10 & 0.02 \\
\hline Only major children & -0.34 & 0.04 & -0.34 & 0.01 \\
\hline Interaction: single \& child younger 18 & -0.14 & 0.03 & -0.14 & 0.02 \\
\hline Interaction: single \& child 18 or older & 0.32 & 0.04 & 0.32 & 0.03 \\
\hline \multicolumn{5}{|l|}{ Interaction: lower secondary \& } \\
\hline child younger 18 & -0.05 & 0.04 & -0.04 & 0.02 \\
\hline \multicolumn{5}{|l|}{ Interaction: upper secondary \& } \\
\hline child younger 18 & -0.02 & 0.06 & 0.00 & 0.02 \\
\hline Interaction: tertiary \& child younger 18 & 0.37 & 0.05 & 0.39 & 0.03 \\
\hline Interaction: period \& child younger 18 & yes & ** & yes & $* *$ \\
\hline \multicolumn{5}{|l|}{ Education } \\
\hline Education woman & yes & $* *$ & yes & $* *$ \\
\hline Education male partner & yes & $* *$ & yes & $* *$ \\
\hline Interaction: woman \& male partner & yes & $* *$ & yes & $* *$ \\
\hline
\end{tabular}

${ }^{a}$ Estimates for the education effects, interaction effects, age, and cohort dummy variables (Model I), and year and age dummy variables (Model II) can be found in appendix A The ${ }^{(* *}$ ' indicate that corresponding dummy variables are jointly significant at the $5 \%$ confidence level (F-test).

b Note that in computing standard errors, we have taken into account that the unemployment variable is not observed at the individual level, but rather per year and per level of education. The standard error for the variable would otherwise be underestimated. 
Table 2: Probability of participation in the labour markt, estimation results for model I (proxy variable approach) and model II (functional form approach) (continued)

\begin{tabular}{|c|c|c|c|c|}
\hline & \multicolumn{2}{|c|}{ Model I } & \multicolumn{2}{|c|}{ Model II } \\
\hline & Est. & S.e. & Est. & S.e. \\
\hline \multicolumn{5}{|l|}{ Age } \\
\hline Dummies & yes & ** & yes & $* *$ \\
\hline \multicolumn{5}{|l|}{ Period (year) } \\
\hline Dummy variables & & & yes & $* *$ \\
\hline Unemployment & -0.05 & 0.01 & & \\
\hline \multicolumn{5}{|c|}{ Cohort (year of birth) } \\
\hline Dummy variables & yes & $* *$ & & \\
\hline Ln(cohort-1924) & & & 1.27 & 0.06 \\
\hline Log likelihood & -272180 & & -272607 & \\
\hline \# Observations & 516298 & & 516298 & \\
\hline
\end{tabular}


Figure 2: Probability of participation 1992-2004 in the presence of children (in \%)

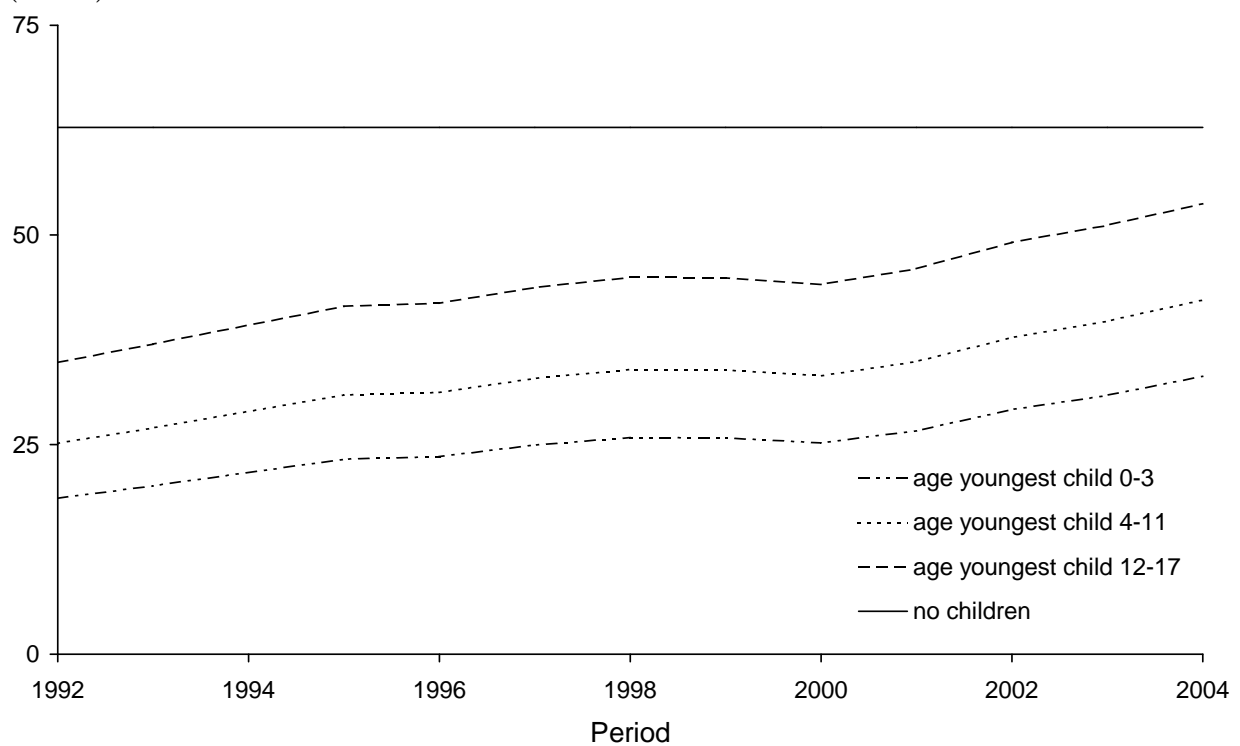

Note: for all characteristics the mean of the data is taken, except for variables with regard to children. Composition effects (over time) are thus purged from the predicted participation rates. 
Figure 3: Probabilities of participation for the 'average' woman with different combinations of education for her and her partner (in \%)

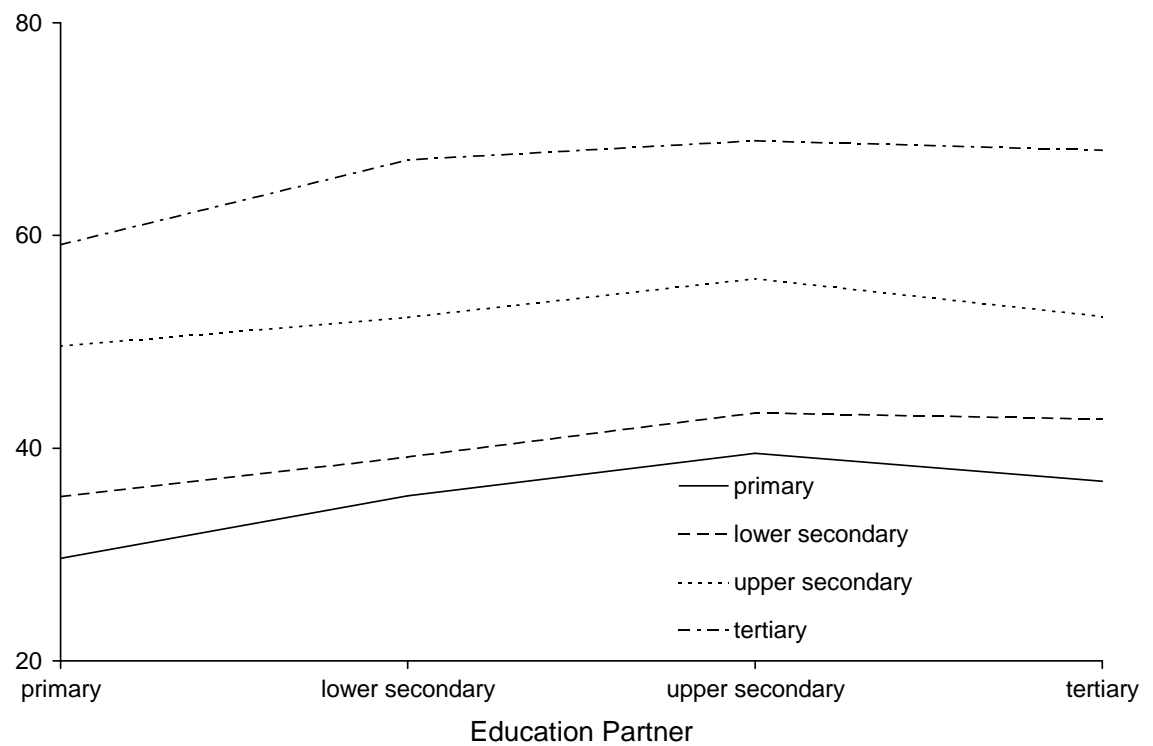

Note: for all characteristics the mean of the data is taken, except for the education variables. 
Figure 4: Estimated profile of unobserved cohort effects, Model I (in \%)

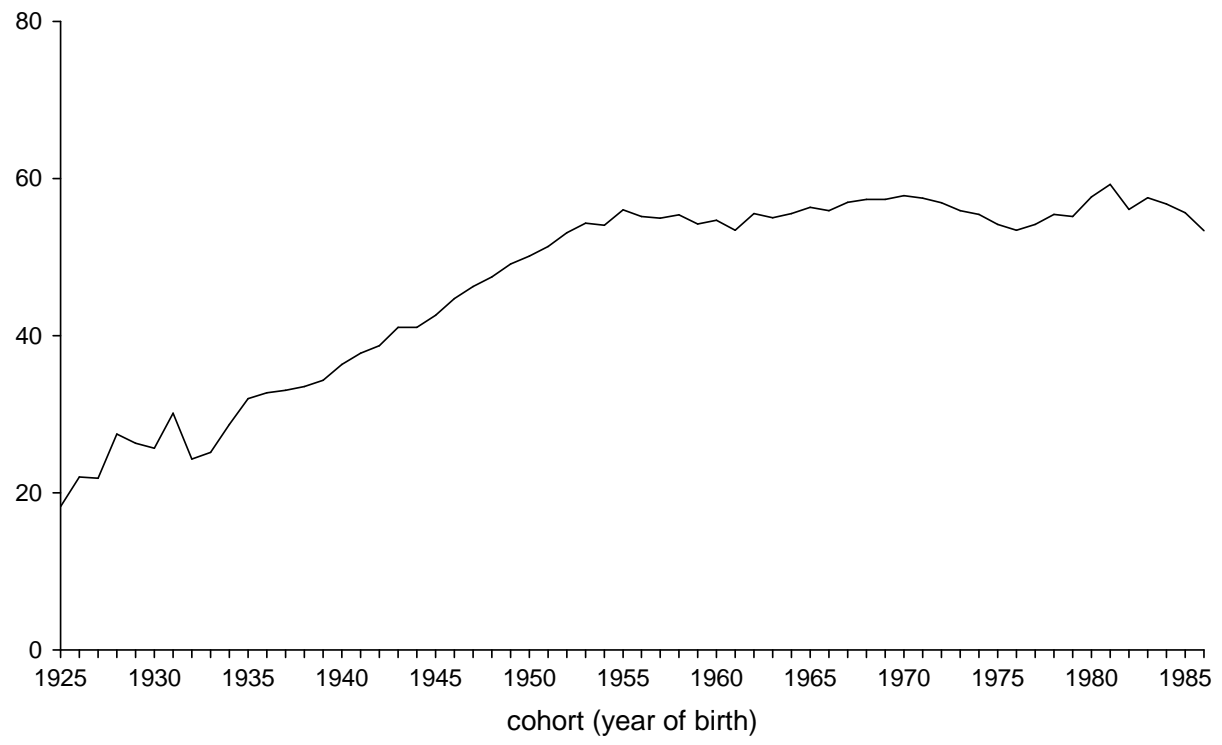

Note: for all characteristics the mean of the data is taken, except for the cohort dummy variables. 
Figure 5: Estimated profile of unobserved age effects, Model I (in \%)

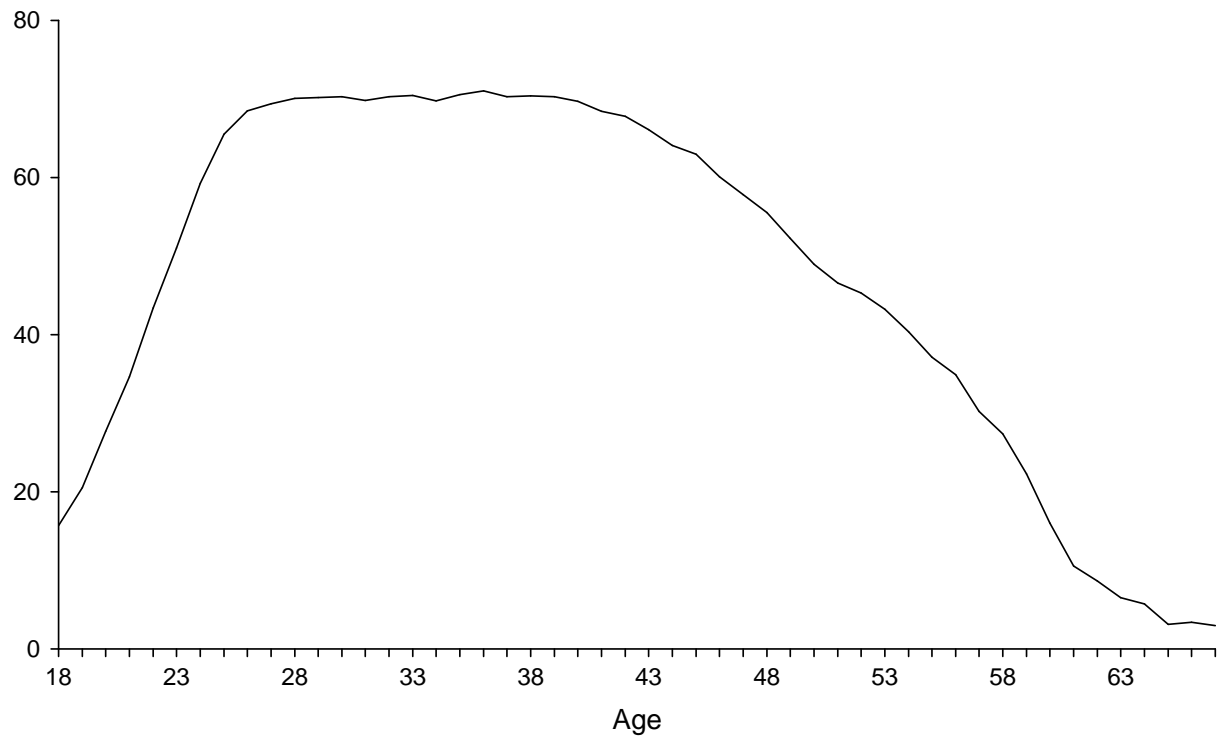

Note: for all characteristics the mean of the data is taken, except for the age dummy variables. 
Figure 6: Actual and predicted growth in the female participation rate (in $\%$-point)

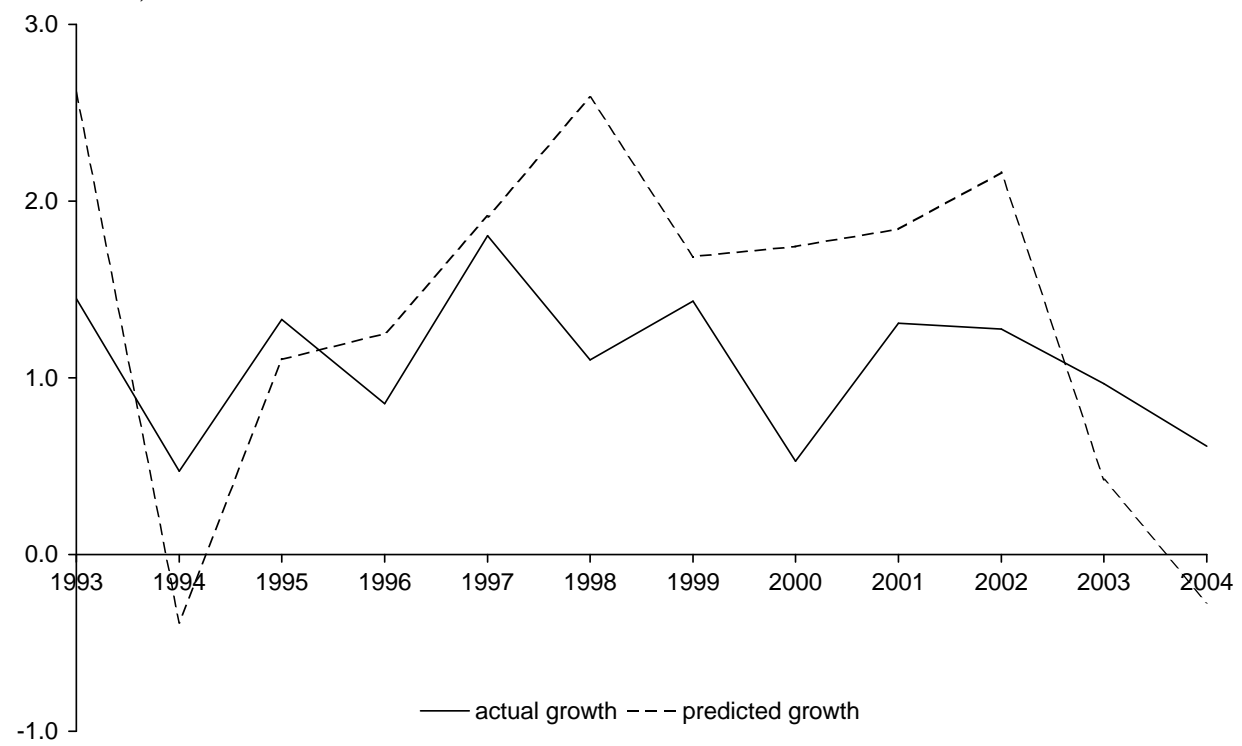

Note: predicted growth rates are based on marginal effects, i.e. first order approximations. Deviations between predicted and actual growth rates may thus be the consequence partly of second and higher order effects. 
Table 3: Decomposition of female participation growth 1992-2004

\begin{tabular}{lrrr}
\hline & $\begin{array}{r}\text { Growth in } \\
\text { participation } \\
\text { rate (\%-points) }\end{array}$ & S.e. ${ }^{\mathrm{b}}$ & $\begin{array}{r}\text { Share } \\
\text { of total } \\
\text { growth (\%) }\end{array}$ \\
\hline Total growth 1992-2004 & 13.1 & & 100 \\
Household position & 0.8 & $(0.0)$ & 6 \\
Having children & -0.1 & $(0.0)$ & -1 \\
Having children * & & & \\
$\quad$ household position & 0.0 & $(0.0)$ & 0 \\
Having children * education & 0.3 & $(0.0)$ & 2 \\
Having children * year & 5.3 & $(1.1)$ & 40 \\
Education & 2.1 & $(0.3)$ & 16 \\
Education partner & 0.3 & $(0.1)$ & 2 \\
Education * education partner & 0.2 & $(0.1)$ & 2 \\
Unemployment & 1.6 & $(0.5)$ & 12 \\
Unobserved age effects & -0.6 & $(0.4)$ & -4 \\
Unobserved cohort effects & 3.3 & $(1.5)$ & 25 \\
\hline
\end{tabular}

${ }^{a}$ Decomposition is based on marginal effects derived from parameter estimates for Model I (reported in tables 26, and 7). Second and higher order effects were spread out over all components according to shares reported in the last column.

${ }^{\mathrm{b}}$ Standard errors were computed according to the Delta method, see equation (6). 
Figure 7: Unobserved age and cohort effects per year (in \%-point)

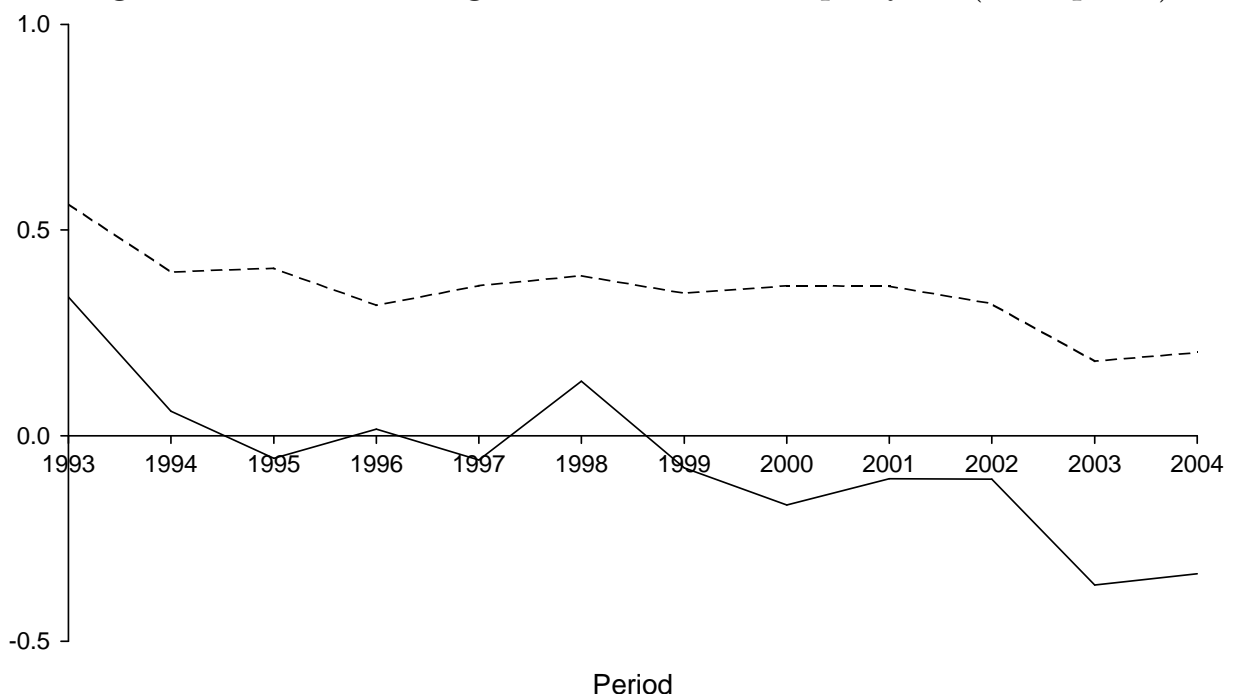

- unobserved age effect - - - unobserved cohort effect 
Table 4: Assumptions made in scenarios

\begin{tabular}{|c|c|}
\hline Variable(s) & Projection assumed \\
\hline Household situation & $\begin{array}{l}\text { More single and cohabiting, less married } \\
\text { women }\end{array}$ \\
\hline Having children & $\begin{array}{l}\text { More households without children; no major } \\
\text { changes in household composition of families } \\
\text { with children }\end{array}$ \\
\hline Having children $*$ year & $\begin{array}{l}\text { Constant (Basic scenario) or change equal to } \\
\text { that during period 1998-2004 (Emancipatory } \\
\text { scenario) }\end{array}$ \\
\hline Education & $\begin{array}{l}\text { Further growth in tertiairy education, less } \\
\text { primary and lower secondary education }\end{array}$ \\
\hline Unemployment & $\begin{array}{l}\text { Convergence towards equilibrium } \\
\text { unemployment rate }\end{array}$ \\
\hline Unobserved age effects & No changes (only compositional effects) \\
\hline Unobserved cohort effects & $\begin{array}{l}\text { No changes compared to cohorts born after } \\
1955 \text { (see figure } 4 \text { ) }\end{array}$ \\
\hline
\end{tabular}


Table 5: Decomposition of projected female participation growth 1992-2050 (\%-points)

\begin{tabular}{|c|c|c|c|}
\hline & \multicolumn{2}{|c|}{$2005-2050$} & \multirow[t]{2}{*}{$1992-2004$} \\
\hline & sc. $B^{a}$ & sc. $E^{\mathrm{a}}$ & \\
\hline Total growth & 7.0 & 9.8 & 13.1 \\
\hline Household position & 1.5 & 1.5 & 0.8 \\
\hline Having children & 1.6 & 1.6 & -0.1 \\
\hline Having children $*$ household position & 0.0 & 0.0 & 0.0 \\
\hline Having children $*$ education & 0.2 & 0.2 & 0.3 \\
\hline Having children $*$ year & 0.0 & 2.9 & 5.3 \\
\hline Education & 1.6 & 1.6 & 2.1 \\
\hline Education partner & -0.1 & -0.1 & 0.3 \\
\hline Education * education partner & 0.4 & 0.4 & 0.2 \\
\hline Unemployment & 1.6 & 1.6 & 1.6 \\
\hline Unobserved age effects & -3.1 & -3.1 & -0.6 \\
\hline Unobserved cohort effects & 3.3 & 3.3 & 3.3 \\
\hline
\end{tabular}

${ }^{\mathrm{a}} \mathrm{B}$ refers to the basic scenario, and $\mathrm{E}$ refers to the emancipatory scenario. 
Table 6: Extended estimation results for table 2, model I (proxy variable approach): age and cohort dummy coefficients ${ }^{\mathrm{a}}$

\begin{tabular}{|c|c|c|c|c|c|c|c|c|}
\hline Var. & Est. & S.e. & Var. & Est. & S.e. & Var. & Est. & S.e. \\
\hline age 18 & & & age 56 & 1.06 & $(0.38)$ & b 1950 & 1.51 & $(0.49)$ \\
\hline age 19 & 0.33 & $(0.07)$ & age 57 & 0.85 & (0.38) & b 1951 & 1.55 & $(0.50)$ \\
\hline age 20 & 0.72 & $(0.10)$ & age 58 & 0.70 & $(0.38)$ & b 1952 & 1.62 & $(0.50)$ \\
\hline age 21 & 1.05 & $(0.13)$ & age 59 & 0.43 & $(0.38)$ & b 1953 & 1.67 & $(0.50)$ \\
\hline age 22 & 1.42 & $(0.15)$ & age 60 & 0.02 & $(0.39)$ & b 1954 & 1.66 & $(0.51)$ \\
\hline age 23 & 1.72 & $(0.16)$ & age 61 & -0.45 & $(0.38)$ & b 1955 & 1.74 & $(0.50)$ \\
\hline age 24 & 2.06 & (0.18) & age 62 & -0.68 & $(0.40)$ & b 1956 & 1.71 & $(0.51)$ \\
\hline age 25 & 2.32 & $(0.20)$ & age 63 & -0.98 & $(0.39)$ & b 1957 & 1.70 & $(0.51)$ \\
\hline age 26 & 2.46 & $(0.21)$ & age 64 & -1.12 & $(0.40)$ & b 1958 & 1.72 & $(0.51)$ \\
\hline age 27 & 2.50 & $(0.23)$ & age 65 & -1.75 & $(0.40)$ & b 1959 & 1.67 & $(0.52)$ \\
\hline age 28 & 2.53 & $(0.25)$ & age 66 & -1.67 & $(0.41)$ & b 1960 & 1.69 & $(0.52)$ \\
\hline age 29 & 2.54 & $(0.26)$ & age 67 & -1.80 & $(0.42)$ & b 1961 & 1.64 & $(0.53)$ \\
\hline age 30 & 2.54 & $(0.26)$ & b 1925 & & & b 1962 & 1.72 & $(0.53)$ \\
\hline age 31 & 2.52 & $(0.27)$ & b 1926 & 0.24 & $(0.35)$ & b 1963 & 1.70 & $(0.53)$ \\
\hline age 32 & 2.54 & $(0.28)$ & b 1927 & 0.23 & $(0.52)$ & b 1964 & 1.72 & (0.53) \\
\hline age 33 & 2.55 & $(0.27)$ & b 1928 & 0.53 & $(0.46)$ & b 1965 & 1.76 & (0.53) \\
\hline age 34 & 2.52 & $(0.28)$ & b 1929 & 0.47 & $(0.46)$ & b 1966 & 1.74 & $(0.53)$ \\
\hline age 35 & 2.56 & $(0.28)$ & b 1930 & 0.44 & $(0.48)$ & b 1967 & 1.78 & $(0.54)$ \\
\hline age 36 & 2.58 & $(0.29)$ & b 1931 & 0.66 & $(0.46)$ & b 1968 & 1.80 & $(0.54)$ \\
\hline age 37 & 2.54 & $(0.29)$ & b 1932 & 0.36 & $(0.45)$ & b 1969 & 1.80 & $(0.55)$ \\
\hline age 38 & 2.55 & $(0.30)$ & b 1933 & 0.41 & $(0.49)$ & b 1970 & 1.82 & $(0.56)$ \\
\hline age 39 & 2.54 & $(0.31)$ & b 1934 & 0.59 & $(0.46)$ & b 1971 & 1.80 & $(0.56)$ \\
\hline age 40 & 2.51 & $(0.31)$ & b 1935 & 0.75 & $(0.49)$ & b 1972 & 1.78 & $(0.56)$ \\
\hline age 41 & 2.46 & $(0.32)$ & b 1936 & 0.78 & $(0.48)$ & b 1973 & 1.74 & $(0.56)$ \\
\hline age 42 & 2.43 & $(0.32)$ & b 1937 & 0.80 & $(0.48)$ & b 1974 & 1.72 & $(0.57)$ \\
\hline age 43 & 2.35 & $(0.33)$ & b 1938 & 0.82 & $(0.48)$ & b 1975 & 1.67 & $(0.55)$ \\
\hline age 44 & 2.26 & $(0.33)$ & b 1939 & 0.85 & $(0.48)$ & b 1976 & 1.64 & $(0.56)$ \\
\hline age 45 & 2.21 & $(0.35)$ & b 1940 & 0.94 & $(0.48)$ & b 1977 & 1.67 & $(0.56)$ \\
\hline age 46 & 2.09 & $(0.35)$ & b 1941 & 1.00 & $(0.48)$ & b 1978 & 1.72 & $(0.57)$ \\
\hline age 47 & 2.00 & $(0.35)$ & b 1942 & 1.04 & $(0.48)$ & b 1979 & 1.71 & $(0.57)$ \\
\hline age 48 & 1.91 & $(0.36)$ & b 1943 & 1.14 & $(0.49)$ & b 1980 & 1.81 & $(0.58)$ \\
\hline age 49 & 1.77 & $(0.36)$ & b 1944 & 1.14 & $(0.48)$ & b 1981 & 1.88 & $(0.60)$ \\
\hline age 50 & 1.64 & $(0.36)$ & b 1945 & 1.20 & $(0.49)$ & b 1982 & 1.75 & (0.61) \\
\hline age 51 & 1.54 & $(0.37)$ & b 1946 & 1.29 & $(0.49)$ & b 1983 & 1.81 & (0.61) \\
\hline age 52 & 1.49 & $(0.37)$ & b 1947 & 1.35 & $(0.49)$ & b 1984 & 1.77 & $(0.63)$ \\
\hline age 53 & 1.41 & $(0.37)$ & b 1948 & 1.40 & $(0.49)$ & b 1985 & 1.73 & $(0.63)$ \\
\hline age 54 & 1.29 & $(0.37)$ & b 1949 & 1.47 & $(0.49)$ & b 1986 & 1.64 & $(0.61)$ \\
\hline age 55 & 1.16 & (0.38) & & & & & & \\
\hline
\end{tabular}

a ' $b$ ' indicates birth year. 
Table 7: Extended estimation results for table 2: education parameters and interaction effects

\begin{tabular}{|c|c|c|c|c|}
\hline \multirow[b]{2}{*}{ Variable } & \multicolumn{2}{|c|}{ Model I ${ }^{\mathrm{a}}$} & \multicolumn{2}{|c|}{ Model $\mathrm{II}^{\mathrm{a}}$} \\
\hline & Est. & S.e. & Est. & S.e. \\
\hline \multicolumn{5}{|l|}{ Minor child(ren) $* 1992$} \\
\hline Minor child(ren) * 1993 & 0.10 & $(0.09)$ & 0.13 & $(0.03)$ \\
\hline Minor child(ren) $* 1994^{\mathrm{b}}$ & -1.13 & $(0.09)$ & -1.10 & $(0.03)$ \\
\hline Minor child(ren) * 1995 & 0.29 & $(0.10)$ & 0.26 & $(0.03)$ \\
\hline Minor child(ren) * 1996 & 0.30 & $(0.11)$ & 0.28 & $(0.03)$ \\
\hline Minor child(ren) * 1997 & 0.38 & $(0.11)$ & 0.31 & $(0.03)$ \\
\hline Minor child(ren) * 1998 & 0.42 & $(0.11)$ & 0.46 & $(0.03)$ \\
\hline Minor child(ren) * 1999 & 0.42 & $(0.11)$ & 0.41 & $(0.03)$ \\
\hline Minor child(ren) $* 2000$ & 0.39 & $(0.11)$ & 0.44 & $(0.03)$ \\
\hline Minor child(ren) $* 2001$ & 0.47 & $(0.12)$ & 0.49 & $(0.03)$ \\
\hline Minor child(ren) * 2002 & 0.59 & $(0.12)$ & 0.56 & $(0.03)$ \\
\hline Minor child(ren) * 2003 & 0.67 & $(0.13)$ & 0.59 & $(0.03)$ \\
\hline Minor child(ren) $* 2004$ & 0.78 & $(0.14)$ & 0.60 & $(0.03)$ \\
\hline \multicolumn{5}{|l|}{ Primary education (E1) } \\
\hline Lower secondary education (E2) & 0.55 & $(0.09)$ & 0.78 & $(0.03)$ \\
\hline Higher secondary education (E3) & 0.73 & $(0.16)$ & 1.09 & $(0.02)$ \\
\hline Tertairy education (E4) & 1.12 & $(0.14)$ & 1.52 & $(0.03)$ \\
\hline Partner: Primary education $(\mathrm{EP} 1)^{\mathrm{c}}$ & -0.13 & $(0.06)$ & -0.14 & $(0.05)$ \\
\hline Partner: Lower secondary educ. $(\mathrm{EP} 2)^{\mathrm{c}}$ & 0.13 & $(0.07)$ & 0.12 & $(0.05)$ \\
\hline Partner: Higher secondary educ. $(\mathrm{EP} 3)^{\mathrm{c}}$ & 0.30 & $(0.06)$ & 0.29 & $(0.05)$ \\
\hline Partner: Tertairy education $(\mathrm{EP} 4)^{\mathrm{c}}$ & 0.19 & $(0.06)$ & 0.18 & $(0.07)$ \\
\hline \multicolumn{5}{|l|}{$\mathrm{E} 1 * \mathrm{EP} 1^{\mathrm{c}}$} \\
\hline \multicolumn{5}{|l|}{$\mathrm{E} 1 * \mathrm{EP} 2^{\mathrm{c}}$} \\
\hline \multicolumn{5}{|l|}{ E1*EP3 ${ }^{\mathrm{c}}$} \\
\hline $\mathrm{E} 1^{*} \mathrm{EP} 4^{\mathrm{c}}$ & & & & \\
\hline
\end{tabular}

${ }^{a}$ Model I refers to the proxy variable approach, and Model II to the functional form approach.

b The interaction effect "Minor child(ren) * 1994" also contains the general effect of having at least one minor child in that year (see the three coefficients on "Age youngest child" in table 2). The reason is that the age of the youngest child in the year 1994 was not observed in the data set.

c It is possible to identify a full set of coefficients for the education level of the partner, because we can use single women as the reference category (for which all related dummy variables equal zero). As a consequence, the coefficients of four interaction dummy variables are not identified and need to be set to zero. 
Table 7: Extended estimation results for table 2 ; education parameters and interaction effects (continued)

\begin{tabular}{|c|c|c|c|c|}
\hline \multirow[b]{2}{*}{ Variable } & \multicolumn{2}{|c|}{ Model I } & \multicolumn{2}{|c|}{ Model II } \\
\hline & Est. & S.e. & Est. & S.e. \\
\hline $\mathrm{E} 2 * \mathrm{EP} 1$ & -0.26 & $(0.06)$ & -0.25 & $(0.04)$ \\
\hline $\mathrm{E} 2 * \mathrm{EP} 2$ & -0.37 & $(0.06)$ & -0.36 & $(0.03)$ \\
\hline $\mathrm{E} 2 * \mathrm{EP} 3$ & -0.37 & $(0.07)$ & -0.35 & $(0.03)$ \\
\hline $\mathrm{E} 2 * \mathrm{EP} 4$ & -0.28 & $(0.06)$ & -0.29 & $(0.06)$ \\
\hline $\mathrm{E} 3 * \mathrm{EP} 1$ & 0.12 & $(0.09)$ & 0.16 & $(0.04)$ \\
\hline $\mathrm{E} 3 * \mathrm{EP} 2$ & -0.04 & $(0.09)$ & 0.00 & $(0.03)$ \\
\hline E3*EP3 & -0.06 & $(0.09)$ & -0.02 & $(0.03)$ \\
\hline $\mathrm{E} 3 * \mathrm{EP} 4$ & -0.09 & $(0.08)$ & -0.07 & $(0.06)$ \\
\hline $\mathrm{E} 4 * \mathrm{EP} 1$ & -0.04 & $(0.13)$ & -0.03 & $(0.09)$ \\
\hline $\mathrm{E} 4 * \mathrm{EP} 2$ & 0.04 & $(0.08)$ & 0.06 & $(0.05)$ \\
\hline $\mathrm{E} 4 * \mathrm{EP} 3$ & -0.05 & $(0.07)$ & -0.03 & $(0.04)$ \\
\hline $\mathrm{E} 4 * \mathrm{EP} 4$ & 0.02 & $(0.06)$ & 0.03 & $(0.06)$ \\
\hline
\end{tabular}


Table 8: Extended estimation results for table 2, model II (functional form approach): year and age dummy coefficients

\begin{tabular}{lrrrrrrrr}
\hline Var. & Est. & S.e. & Var. & Est. & S.e. & Var. & Est. & S.e. \\
\hline 1992 & & & age 26 & 2.73 & $(0.04)$ & age 47 & 2.70 & $(0.06)$ \\
1993 & -0.05 & $(0.02)$ & age 27 & 2.80 & $(0.04)$ & age 48 & 2.61 & $(0.06)$ \\
1994 & -0.10 & $(0.02)$ & age 28 & 2.86 & $(0.04)$ & age 49 & 2.48 & $(0.06)$ \\
1995 & -0.12 & $(0.02)$ & age 29 & 2.89 & $(0.04)$ & age 50 & 2.35 & $(0.07)$ \\
1996 & -0.14 & $(0.03)$ & age 30 & 2.92 & $(0.04)$ & age 51 & 2.26 & $(0.07)$ \\
1997 & -0.10 & $(0.03)$ & age 31 & 2.91 & $(0.04)$ & age 52 & 2.20 & $(0.07)$ \\
1998 & -0.18 & $(0.03)$ & age 32 & 2.95 & $(0.04)$ & age 53 & 2.12 & $(0.07)$ \\
1999 & -0.08 & $(0.03)$ & age 33 & 2.98 & $(0.04)$ & age 54 & 2.00 & $(0.08)$ \\
2000 & -0.11 & $(0.03)$ & age 34 & 2.97 & $(0.04)$ & age 55 & 1.87 & $(0.08)$ \\
2001 & -0.07 & $(0.03)$ & age 35 & 3.03 & $(0.04)$ & age 56 & 1.78 & $(0.08)$ \\
2002 & -0.04 & $(0.03)$ & age 36 & 3.07 & $(0.04)$ & age 57 & 1.57 & $(0.08)$ \\
2003 & -0.04 & $(0.04)$ & age 37 & 3.06 & $(0.04)$ & age 58 & 1.44 & $(0.09)$ \\
2004 & -0.04 & $(0.04)$ & age 38 & 3.09 & $(0.05)$ & age 59 & 1.18 & $(0.09)$ \\
age 18 & & & age 39 & 3.11 & $(0.05)$ & age 60 & 0.79 & $(0.10)$ \\
age 19 & 0.37 & $(0.03)$ & age 40 & 3.11 & $(0.05)$ & age 61 & 0.35 & $(0.11)$ \\
age 20 & 0.80 & $(0.03)$ & age 41 & 3.07 & $(0.05)$ & age 62 & 0.16 & $(0.11)$ \\
age 21 & 1.17 & $(0.03)$ & age 42 & 3.06 & $(0.05)$ & age 63 & -0.10 & $(0.12)$ \\
age 22 & 1.57 & $(0.04)$ & age 43 & 3.00 & $(0.05)$ & age 64 & -0.18 & $(0.13)$ \\
age 23 & 1.92 & $(0.04)$ & age 44 & 2.93 & $(0.05)$ & age 65 & -0.69 & $(0.16)$ \\
age 24 & 2.27 & $(0.04)$ & age 45 & 2.90 & $(0.06)$ & age 66 & -0.49 & $(0.17)$ \\
age 25 & 2.57 & $(0.04)$ & age 46 & 2.79 & $(0.06)$ & age 67 & -0.52 & $(0.18)$ \\
\hline
\end{tabular}

